Article

\title{
Hybrid Electroluminescence Devices with Solution-Processed Mixed Emitting Layers of Red Quantum Dots and Blue Small Molecules
}

\author{
So Eun Ju, Chang Gi Yoon and Jiwan Kim * D \\ Department of Advanced Materials Engineering, Kyonggi University, Suwon 16227, Korea; \\ jusoy95@naver.com (S.E.J.); wendy117@naver.com (C.G.Y.) \\ * Correspondence: jiwank@kgu.ac.kr
}

Received: 29 May 2020; Accepted: 1 July 2020; Published: 2 July 2020

check for updates

\begin{abstract}
Hybrid electroluminescence (EL) devices with mixed emission layers (EMLs) were developed to achieve balanced peaks from red quantum dots (QDs) and blue phosphorescent small molecules. The EML was prepared by mixing QDs and small molecules in an organic solvent, and then adding polystyrene to disrupt the aggregation of the host material. These unique bichromatic devices exhibited two distinct EL peaks with similar intensities over $10 \mathrm{~V}$, and the voltage dependent EL spectra were investigated systematically. These hybrid EL devices showed a maximum luminance of $1057.7 \mathrm{~cd} / \mathrm{m}^{2}$ and a current efficiency of $2.45 \mathrm{~cd} / \mathrm{A}$. These results indicate that the unique mixed EMLs have potential for use as white devices using fewer fabrication steps.
\end{abstract}

Keywords: colloidal quantum dots; organic small molecules; electroluminescence

\section{Introduction}

Colloidal quantum dots (QD) have an adjustable emission wavelength, through size-control, with high color purity and their outer organic ligands make the fabrication process cost effective by the solution process [1-4]. For this reason, QDs are promising semiconductor emitters for the future display industry, and the performance of quantum dot light-emitting diodes (QLEDs) is now comparable with that of organic light-emitting diodes (OLEDs) because of the advantages of a narrow emission line and enhanced electroluminescence (EL) characteristics [5-7].

Compared to monochromatic devices, studies on white-emitting QLEDs have been limited owing to the structural complexity of the device and the difficulty in simultaneous multi-emission. The stacked tandem structure is considered the way to achieve white emission as in the case of white-emitting OLEDs. However, its complicated fabrication requires further attention because of its in-between buffer layers and multiple emission layers (EMLs) [8,9]. Other attempts using mixed EMLs using more than two QDs have been made, but the inevitable energy loss to adjacent QDs is difficult to control $[10,11]$. Studies about organic and inorganic hybridization for white EL have been limited. White light-emitting diodes with a hybrid polymer and QDs have been reported, but the luminance was less than $500 \mathrm{~cd} / \mathrm{m}^{2}$ [12,13]. Recently, our group reported highly efficient white QLEDs with blue and green mixed QDs and red organic phosphorescent molecules. They had a maximum luminance of $20,453 \mathrm{~cd} / \mathrm{m}^{2}$ and an external quantum efficiency (EQE) of 9.19\% [14]. However, the fabrication process for two EMLs consists of two different deposition methods-spin coating and thermal evaporation.

Although vacuum deposition is the most commonly employed process for the fabrication of EL devices, the equipment is very expensive, and the efficiency of the deposited material is as low as approximately $10 \%$. These problems can be critical in large panels. Recently, the solution process in OLEDs has received considerable attention as a result of the low manufacturing cost, and 
high utilization efficiency of the deposited material by minimizing the use of materials, and their performance is comparable with that of conventional, vacuum-processed devices [15]. Shinar et al. successfully fabricated a green OLED by spin coating one of the solution processes and achieved an efficiency of $69 \mathrm{~cd} / \mathrm{A}$ [16].

Herein, we report hybrid EL devices with solution-processed EMLs using red QDs and blue phosphorescent molecules. Because blue remains a weak point in QDs, we chose QDs for red emission and small molecules for blue emission. Firstly, small-molecule host materials and blue dopant materials were dispersed in an organic solvent, and then a unique solution-processed EML was prepared by mixing it with red QDs. As most small-molecule materials exhibit poor film-forming properties owing to molecular aggregation, a small amount of polystyrene (PS) was added to the mixed solution to suppress this. Hybrid EL devices with the addition of small amounts of PS showed better optoelectrical performance with stable film morphology.

\section{Materials and Methods}

\subsection{Synthesis of Red QDs}

Red emitting CdSeS/ZnS QDs were prepared by the synthesis procedure in the recent publication of Yang's group [11]. Briefly, a mixture of $1.1 \mathrm{mmol}$ of $\mathrm{Cd}$ acetate and $5 \mathrm{~mL}$ of oleic acid (OA) was degassed and heated to $150^{\circ} \mathrm{C}$, followed by the addition of $20 \mathrm{~mL}$ of 1-octadecene (ODE) and further heating to $305^{\circ} \mathrm{C}$. At that temperature, an anionic stock solution, prepared by dissolving $0.27 \mathrm{mmol}$ of Se and $0.03 \mathrm{mmol}$ of $\mathrm{S}$ in $0.3 \mathrm{~mL}$ of trioctylphosphine (TOP), was quickly injected. And then the reaction was maintained for $90 \mathrm{~s}$ for CdSeS core growth, followed by a dropwise addition of $1.7 \mathrm{mmol}$ of 1-octanethiol. For the $\mathrm{ZnS}$ shelling, a $\mathrm{Zn}$ solution with $2.86 \mathrm{mmol}$ of $\mathrm{Zn}$ acetate dihydrate dissolved in $4 \mathrm{~mL}$ of $\mathrm{OA}$ and $1 \mathrm{~mL}$ of ODE was first injected and a $\mathrm{S}$ solution with $6.75 \mathrm{mmol}$ of $\mathrm{S}$ dissolved in $3.5 \mathrm{~mL}$ of TOP was then injected. The absorption and photoluminescence (PL) spectra and X-ray diffraction (XRD) patterns of red CdSeS/ZnS QDs are shown in Figure 1 [17].

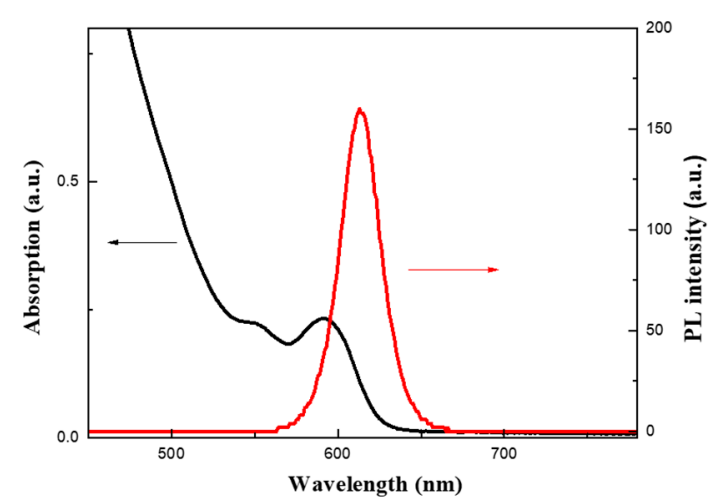

(a)

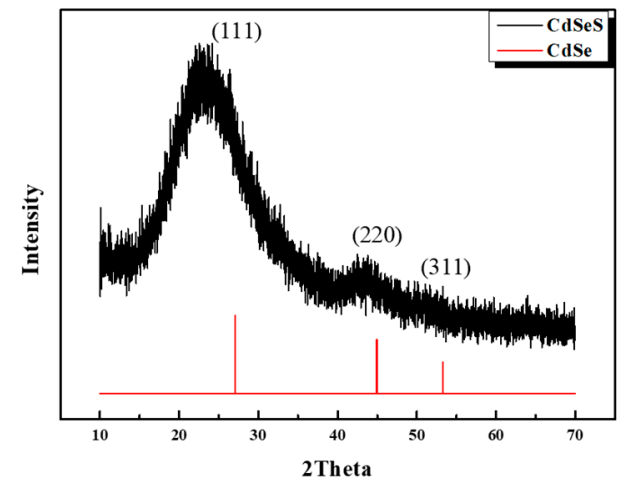

(b)

Figure 1. (a) Absorption and photoluminescence spectra and (b) X-ray diffraction (XRD) patterns of CdSeS/ZnS QDs.

\subsection{Fabrication of $Q L E D S$}

A patterned indium-tin oxide (ITO) glass was cleaned by sonication using isopropyl alcohol and deionized water. The surface of the pre-cleaned ITO glass was subjected to an ultraviolet (UV) plasma treatment for $15 \mathrm{~min}$. For a device with an inverted structure, the electron transport layer (ETL) of ZnO nanoparticles (NPs) in ethanol was spin-coated on the cleaned ITO glass. The organic molecule of 1,3-Bis $(\mathrm{N}$-carbazolyl)benzene $(\mathrm{mCP})$ was used as the host material and Bis[2-(4,6-difluorophenyl)pyridinato-C2,N](picolinato) iridium(III) (FIrpic) was used as the dopant for the mixed EML. Then, mCP:FIrpic was mixed in a 10:1 weight ratio and dissolved in toluene to be mixed again with red CdSeS/ZnS CQDs. The QD solution and organic solution were mixed in 1:3 and 
1:5 volume ratios, respectively. The polystyrene was dissolved separately in chlorobenzene to prepare a solution of $20 \mathrm{mg} / \mathrm{mL}$ concentration. Afterwards, a $10 \mathrm{wt} . \%$ polystyrene solution was added. To deposit EML, the solution of mixed QDs, organic phosphors, and polystyrene was spin-coated on the ZnO layer at a spin rate of $2000 \mathrm{rpm}$ for $5 \mathrm{~s}$ After the solution process, 4,4'-Bis(N-carbazolyl)-1,1'-biphenyl (CBP) was directly deposited onto the EML to a thickness of $40 \mathrm{~nm}$, using vacuum evaporation. Then, the cathode $\left(\mathrm{MoO}_{3}\right.$ and $\left.\mathrm{Al}\right)$ was deposited by thermal evaporation to thicknesses of $10 \mathrm{~nm}$ and $100 \mathrm{~nm}$, respectively. Finally, the devices were encapsulated by an encapsulation glass using an UV sealant.

\subsection{Characterization}

The current density-voltage-luminance (J-V-L) characteristics of the fabricated devices were measured using a spectroradiometer (Minolta CS 2000, Tokyo, Japan) with a Keithley 2400 source meter under ambient conditions. From these J-V-L measurements, the changes in the devices' luminance, current efficiency and electroluminescence spectrum as a function of the applied voltage were studied systematically. The surface roughness was measured by atomic force microscopy (AFM, PSIA XE-100, Suwon, Korea). An aluminum coated silicon cantilever (NCHR-50, Nanoworld AG, $42 \mathrm{~N} / \mathrm{m}, 320 \mathrm{kHz}$, Neuchatel, Switzerland) was used for non-contact mode measurement.

\section{Results and Discussion}

Figure 2 illustrates a schematic diagram of hybrid EL devices, which consists of ITO/ZnO NPs $(50 \mathrm{~nm}) / \mathrm{red}$ QDs + mCP:FIrpic (mixed EML) $(30 \mathrm{~nm}) / \mathrm{CBP}(40 \mathrm{~nm}) / \mathrm{MoO}_{3}(10 \mathrm{~nm}) / \mathrm{Al}$. The inverted device structure was chosen for efficient injection of electrons and holes into the EML. ZnO NPs are representative inorganic materials as an ETL for QLEDs, because their conduction band minimum is well-matched with the work function of the ITO electrode and they are robust against various organic solvents [18]. In this study, a unique mixed EML was designed for simultaneous red and blue emissions from the QDs and FIrpic, respectively. It is well known that phosphorescent OLED devices have a host-dopant system to efficiently transfer exciton energy, and $\mathrm{mCP}$ was selected as the host for the blue emitting dopant, FIrpic. However, $\mathrm{mCP}$ is mainly used in conventional, vacuum-processed OLEDs owing to the crystallization during solution processing caused by the low glass transition temperature and symmetric molecular structure [15]. To diminish this aggregation, the electrically isolating PS was dissolved separately and then added to the mixed EML.

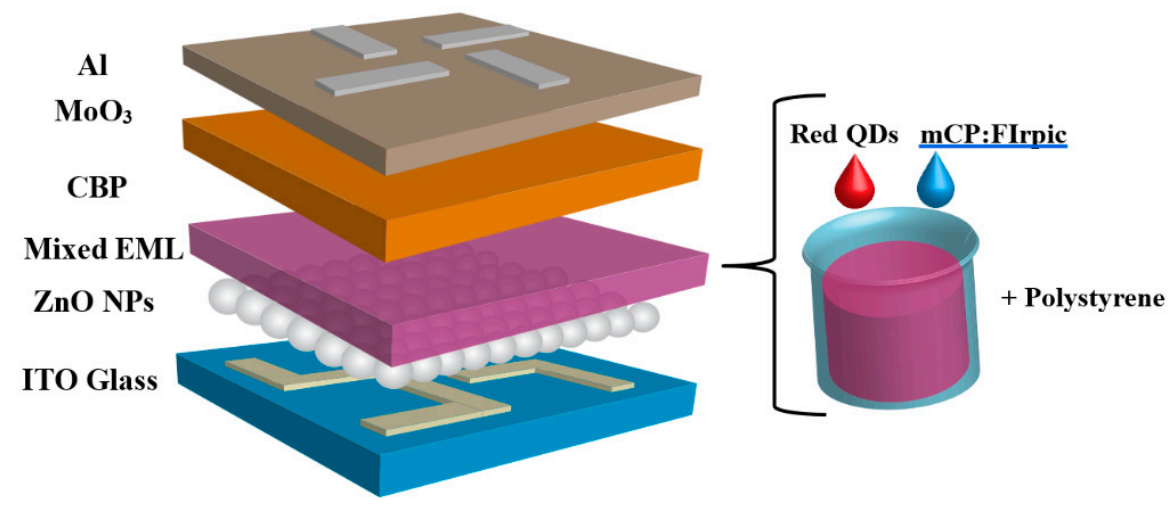

Figure 2. Schematic of hybrid electroluminescence (EL) devices with mixed emission layers (EMLs) of red quantum dots (QDs) and blue small molecules.

Figure 3 shows the EL spectra of hybrid EL devices with mixed EMLs. Two distinct peaks (blue from FIrpic and red from QDs) are simultaneously observed at an applied voltage of $10 \mathrm{~V}$. Different mixing ratios of QD and organic solution in the EML were compared, and similar EL intensities from red QDs and blue FIrpic were obtained using a mixing ratio of 1:5. As QDs with organic ligands are 
more stable than FIrpic in the organic solvent and the emission from FIrpic needs an exciton energy transfer from $\mathrm{mCP}$, it is reasonable to conclude that more FIrpic is needed for balanced EL peaks.

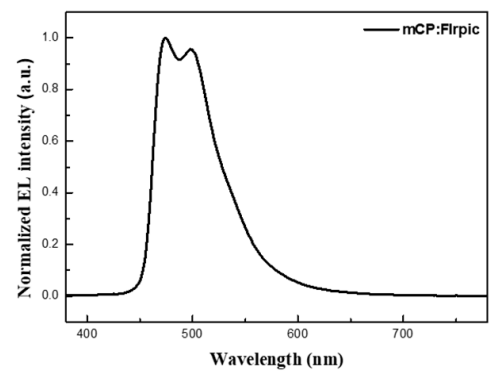

(a)

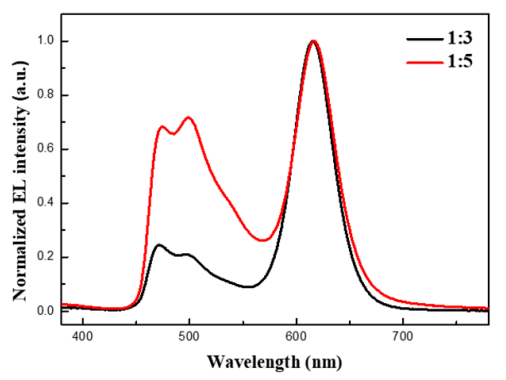

(b)

Figure 3. EL spectra of (a) the monochromatic EL device with only 1,3-Bis(N-carbazolyl)benzene $(\mathrm{mCP})$ :Bis[2-(4,6-difluorophenyl)pyridinato-C2,N](picolinato) iridium(III) (FIrpic) and (b) the bichromatic hybrid EL device with mixed EMLs at $10 \mathrm{~V}$.

Figure 4 shows the optoelectronic properties of hybrid EL devices with the mixed EML (red QDs:blue FIrpic $=1: 5$ ) to verify the role of the PS additive. In Figure 4a, the hybrid EL device without PS shows a constant ohmic trend with increasing applied voltage. After adding PS in the mixed EML, the current density-voltage curve shifted to lower currents, because electrically isolating PS disrupted the charge carrier transport [19]. Therefore, it leads to an increment of both the turn-on voltage (from 3.5 to $4.5 \mathrm{~V}$ ) and current efficiency (from 0.33 to $2.45 \mathrm{~cd} / \mathrm{A}$ ), respectively, as shown in Figure $4 \mathrm{~b}, \mathrm{c}$. The peak luminance of $1057.7 \mathrm{~cd} / \mathrm{m}^{2}$ was achieved at $13 \mathrm{~V}$ (corresponding to a current density of $293 \mathrm{~mA} / \mathrm{cm}^{2}$ ) and current efficiency of $2.45 \mathrm{~cd} /$ A were obtained at a current density of $0.13 \mathrm{~mA} / \mathrm{cm}^{2}$.

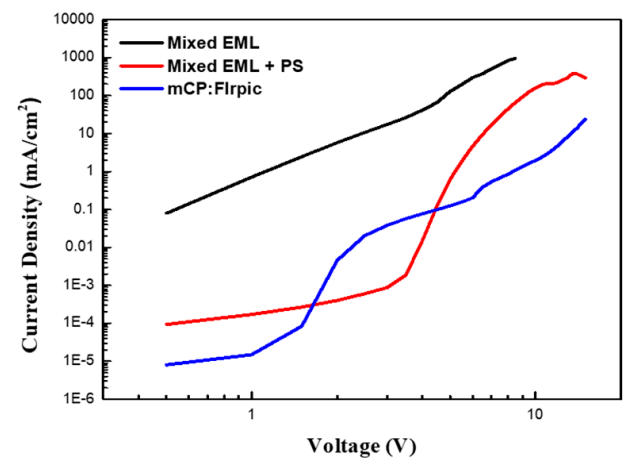

(a)

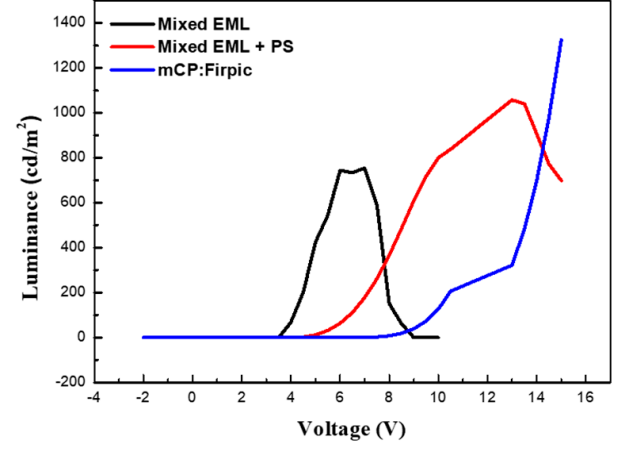

(b)

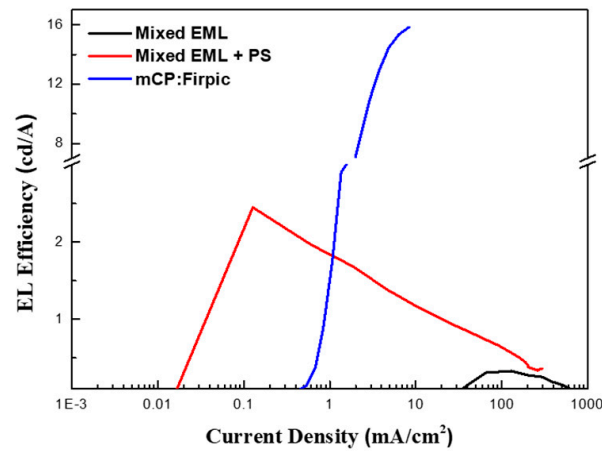

(c)

Figure 4. (a) Current density-voltage; (b) luminance-voltage; and (c) current efficiency-current density characteristics of monochromatic EL devices with mCP:FIrpic and hybrid EL devices with mixed EMLs and added PS. 
Figure 5 shows the AFM images of the mixed EML (red QDs:blue FIrpic 1:5) to investigate the effect of added PS. Prior to fabrication of the whole QLEDs, the mixed EML was deposited on the $\mathrm{ZnO} / \mathrm{ITO}$ glass to compare the surface roughness with and without PS addition. The surface roughness of the mixed EML decreased from 1.627 to $0.733 \mathrm{~nm}$ with the PS addition because of the effective suppression of the mCP aggregation [19].
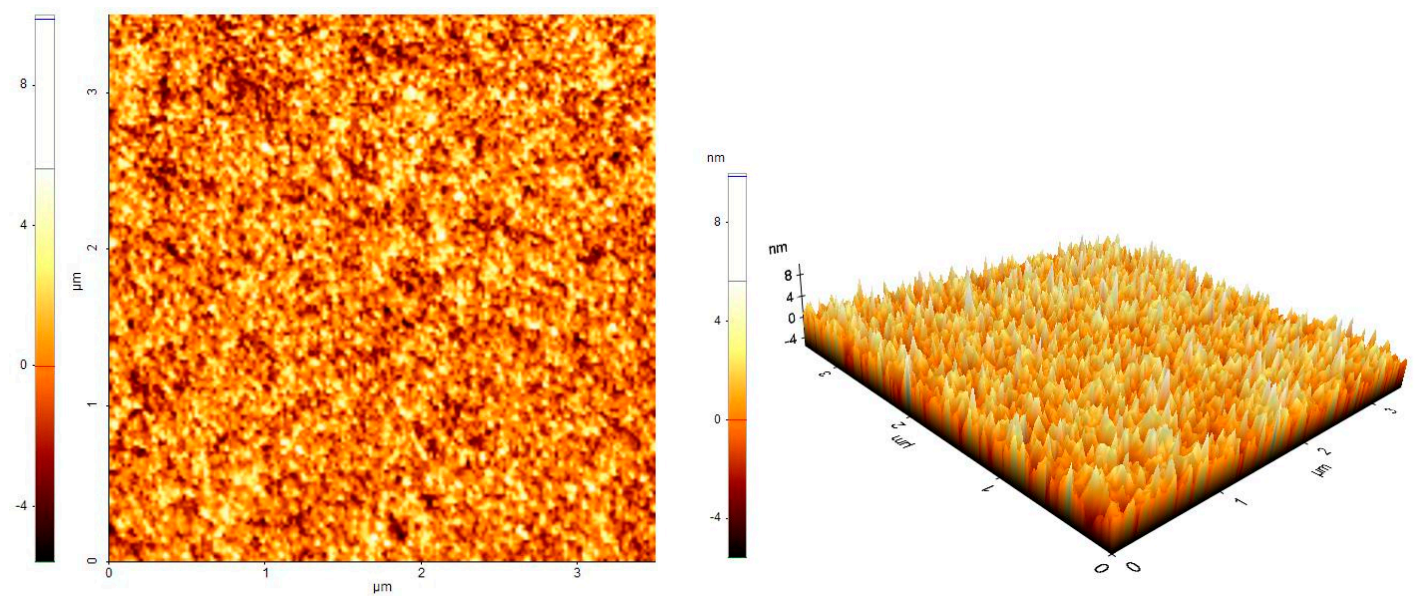

(a)
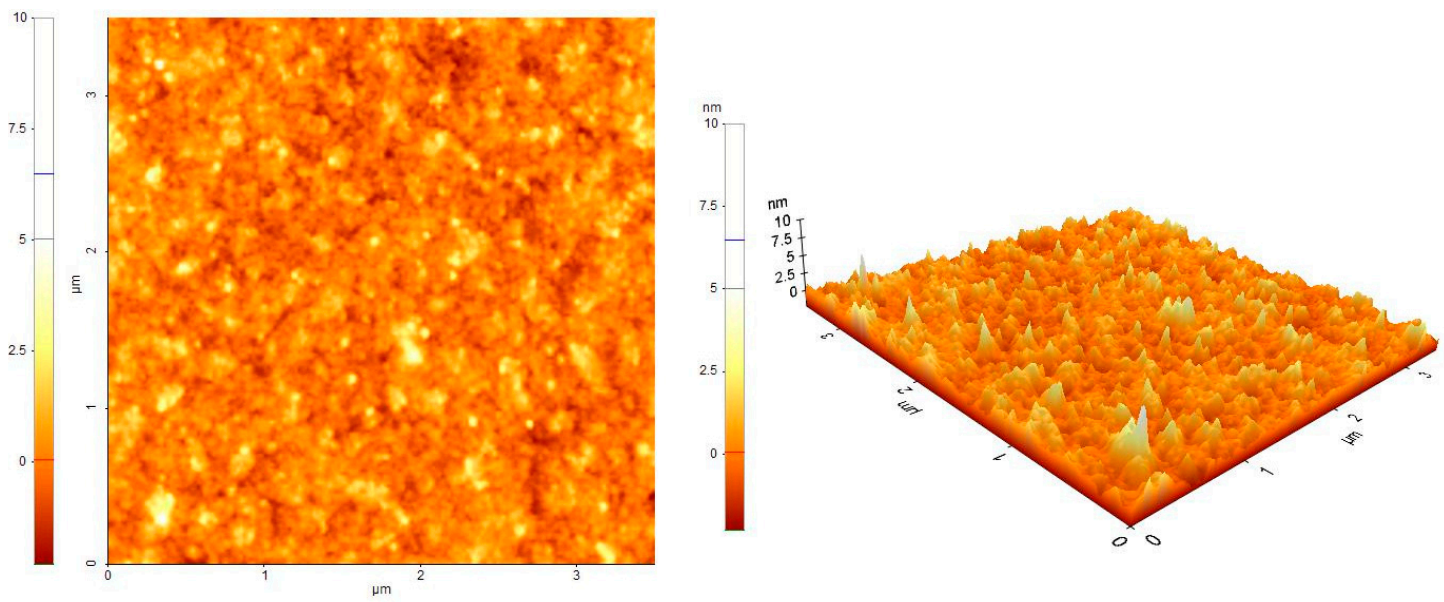

(b)

Figure 5. Atomic force microscopy (AFM) images of mixed EMLs on the ZnO/ITO glass: (a) without PS $\left(R_{\mathrm{q}}=1.627 \mathrm{~nm}\right)$ and $(\mathbf{b})$ with PS $\left(\mathrm{R}_{\mathrm{q}}=0.733 \mathrm{~nm}\right)$.

The spectral variation in the EL spectra and the shift in the Commission Internationale de 1'Eclairage (CIE) coordinates of hybrid EL devices with the mixed EML (red QDs:blue FIrpic 1:5) at different voltages are shown in Figure 6. In Figure 6a, the EL intensity from blue FIrpic is appoximately half that of the red QDs and the peak intensity was observed at $6 \mathrm{~V}$. As shown in Figure 4a, an extremely high current density of hybrid EL devices without PS leads to unstable optoelectrical characteristics, such as early turn-on and sudden turn-off. Since the EL peak from red QDs is dominant and the intensity ratio between blue and red peaks is similar to increasing voltage, the CIE coordinate mainly stays in the red region with a small shift in Figure 6c. On the contrary, the hybrid EL devices with PS show balanced EL peaks above $10 \mathrm{~V}$ from both blue FIrpic and red QDs. The CIE coordinate moves to the white region with increasing voltage, as a result of the later blue emission of FIrpic. This is attributed to the large bandgap of FIrpic leading to effective emission in the higher voltage region. 


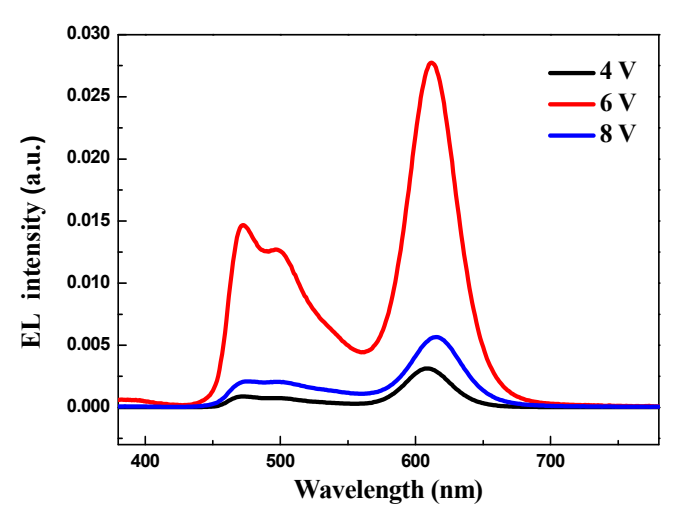

(a)

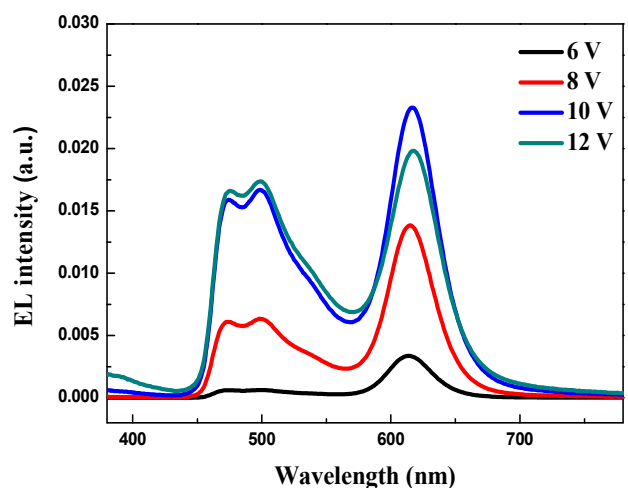

(b)

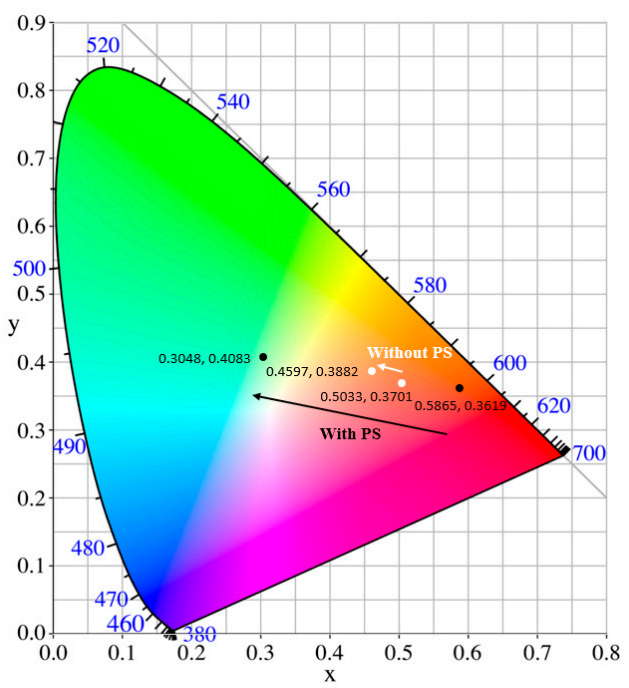

(c)

Figure 6. Voltage-dependent spectra of hybrid EL devices: (a) without PS and (b) with PS. (c) Shifts in Commission Internationale de l'Eclairage (CIE) coordinates of hybrid EL devices as applied voltage increases.

Although the performance of the hybrid EL devices with the mixed EML does not match with the high-performance of recent QLEDs, these hybrid EL devices demonstrate a novel method to create white light over the traditional tandem structure. QDs are easy to apply to solution processes, however, efficient blue emission requires further work. Small molecules have been well-studied for EL applications, but the solution process is not the main process for practical manufacturing. While the hybridization of organic and inorganic materials for white emission can take advantage of each, the complicated interface between them results in low performance and unstable devices $[12,13,20]$. In this work, the present hybrid EL devices successfully showed two distinct emissions simultaneously from the mixed EML and the balanced EL peaks under higher applied voltage were achieved with the addition of PS. Since the limitation of charge injection into QDs and small molecules are different, more precise optimization is required for white emission with high color rendering index. Combining the advantages of QDs and small molecules in the solution based EML can reduce the fabrication cost and give the flexibility for future large-area white emitting EL devices.

\section{Conclusions}

Hybrid EL devices with mixed EMLs employing QDs and small molecules were successfully fabricated. The EL spectra showed a distinct blue emission from FIrpic and a distinct red emission from QDs simultaneously, and similar EL intensities were observed at a ratio of 1:5 (QDs:FIrpic). After 
adding PS to $\mathrm{mCP}$, the hybrid EL devices had a maximum luminance of $1057.7 \mathrm{~cd} / \mathrm{m}^{2}$, while emitting the balanced white light. Stable optoelectrical properties were obtained because electrically isolating PS effectively hinders the flow of charge. The mixed EML prepared in the solution process showed balanced peaks from inorganic QDs (red) and organic mCP:FIrpic (blue), which is a promising result for solution based white emitting EL devices.

Author Contributions: Investigation, S.E.J. and C.G.Y.; writing—original draft preparation, S.E.J.; writing一review and editing, J.K.; supervision, J.K.; funding acquisition, J.K. All authors have read and agreed to the published version of the manuscript.

Funding: This research was financially supported by the Ministry of Trade, Industry and Energy and Korea Institute for Advancement of Technology through the International Cooperative R\&D program (P0011268). This work was also supported by the Materials Innovation Project (2020M3H4A3082656) funded by National Research Foundation of Korea and World Class 300 Project R\&D grant (S2434857) by Korea Small and Medium Business Administration.

Conflicts of Interest: The authors declare no conflict of interest.

\section{References}

1. Colvin, V.L.; Schlamp, M.C.; Alivisatos, A.P. Light-emitting diodes made from cadmium selenide nanocrystals and a semiconducting polymer. Nature 1994, 370, 354-357. [CrossRef]

2. Yang, Y.X.; Zheng, Y.; Cao, W.R.; Titov, A.; Hyvonen, J.; Manders, J.R.; Xue, J.G.; Holloway, P.H.; Qian, L. High-efficiency light-emitting devices based on quantum dots with tailored nanostructures. Nat. Photonics 2015, 9, 259-266. [CrossRef]

3. BMashford, B.S.; Stevenson, M.; Popovic, Z.; Hamilton, C.; Zhou, Z.; Breen, C.; Steckel, J.; Bulovic, V.; Bawendi, M.; Coe-Sullivan, S.; et al. High-efficiency quantum-dot light-emitting devices with enhanced charge injection. Nat. Photonics 2013, 7, 407-412. [CrossRef]

4. Qian, L.; Zheng, Y.; Xue, J.; Holloway, P.H. Stable and efficient quantum-dot light-emitting diodes based on solution-processed multilayer structures. Nat. photonics 2011, 5, 543-548. [CrossRef]

5. Dai, X.L.; Zhang, Z.X.; Jin, Y.Z.; Niu, Y.; Cao, H.J.; Liang, X.Y.; Chen, L.W.; Wang, J.P.; Peng, X.G. Solution-processed, high-performance light-emitting diodes based on quantum dots. Nature 2014, 515, $96-99$. [CrossRef] [PubMed]

6. Lee, K.-H.; Lee, J.H.; Song, W.S.; Ko, H.; Lee, C.; Yang, H. Highly efficient, color-pure, color-stable blue quantum dot light-emitting devices. ACS Nano 2013, 7, 7295-7302. [CrossRef] [PubMed]

7. Won, Y.-H.; Cho, O.; Kim, T.; Chung, D.-Y.; Kim, T.; Chung, H.; Jang, H.; Lee, J.; Kim, D.; Jang, E. Highly efficient and stable InP/ZnSe/ZnS quantum dot light-emitting diodes. Nature 2019, 575, 634-638. [CrossRef] [PubMed]

8. Lee, K.-H.; Han, C.-Y.; Jang, E.-P.; Jo, J.-H.; Hong, S.; Hwang, J.Y.; Choi, E.; Hwang, J.-H.; Yang, H. Full-color capable light-emitting diodes based on solution-processed quantum dot layer stacking. Nanoscale 2018, 10, 6300-6305. [CrossRef] [PubMed]

9. Zhang, H.; Wang, S.T.; Sun, X.W.; Chen, S.M. All solution-processed white quantum-dot light-emitting diodes with three-unit tandem structure. J. Soc. Inf. Disp. 2017, 25, 143-150. [CrossRef]

10. Bae, W.K.; Lim, J.; Lee, D.; Park, M.; Lee, H.; Kwak, J.; Char, K.; Lee, C.; Lee, S. R/G/B/natural white light thin colloidal quantum dot-based light-emitting devices. Adv. Mater. 2014, 26, 6387-6393. [CrossRef] [PubMed]

11. Lee, K.-H.; Han, C.-Y.; Kang, H.-D.; Ko, H.; Lee, C.; Lee, J.; Myoung, N.; Yim, S.-Y.; Yang, H. Highly efficient, color-reproducible full-color electroluminescent devices based on red/green/blue quantum dot-mixed multilayer. ACS Nano 2015, 9, 10941-10949. [CrossRef] [PubMed]

12. Son, D.I.; You, C.H.; Kim, W.T.; Kim, T.W. White light-emitting diodes fabricated utilizing hybrid polymer-colloidal ZnO quantum dots. Nanotechnology 2009, 20, 365206. [CrossRef] [PubMed]

13. Zhang, Y.; Xie, C.; Su, H.; Liu, J.; Pickering, S.; Wang, Y.; Yu, W.W.; Wang, J.; Wang, Y.; Hahm, J.-I.; et al. Employing heavy metal-free colloidal quantum dots in solution-processed white light-emitting diodes. Nano Lett. 2011, 11, 329-332. [CrossRef] [PubMed]

14. Oh, S.; Han, C.Y.; Yang, H.; Kim, J. Highly efficient white electroluminescent devices with hybrid double emitting layers of quantum dots and phosphorescent molecules. Nanoscale 2019, 11, 9276-9280. [CrossRef] [PubMed] 
15. Yook, K.S.; Lee, J.Y. Small molecule host materials for solution processed phosphorescent organic light-emitting diodes. Adv. Mater. 2014, 26, 4218-4233. [CrossRef] [PubMed]

16. Cai, M.; Xiao, T.; Hellerich, E.; Chen, Y.; Shinar, R.; Shinar, J. High-efficiency solution-processed small molecule electrophosphorescent organic light-emitting diodes. Adv. Mater. 2011, 23, 3590-3596. [CrossRef] [PubMed]

17. Zhan, H.-J.; Zhou, P.-J.; He, Z.-Y.; Tian, Y. Microwave-assisted aqueous synthesis of small-sized, highly luminescent CdSeS/ZnS core/shell quantum dots for live cell imaging. Eur. J. Inorg. Chem. 2012, 15, 2487-2493. [CrossRef]

18. Jang, I.; Kim, J.; Ippen, C.; Greco, T.; Oh, M.S.; Lee, J.; Kim, W.K.; Wedel, A.; Han, C.J.; Park, S.K. Inverted InP quantum dot light-emitting diodes using low-temperature solution-processed metal-oxide as an electron transport layer. Jpn. J. Appl. Phys. 2014, 54, 02BC01. [CrossRef]

19. Höfle, S.; Pfaff, M.; Do, H.; Bernhard, C.; Gerthsen, M.; Lemmer, U.; Colsmann, A. Suppressing molecular aggregation in solution processed small molecule organic light emitting diodes. Org. Electron. 2014, 15, 337-341. [CrossRef]

20. Huang, C.-Y.; Huang, S.-J.; Liu, M.-H.M. Hybridization of $\mathrm{CsPbBr}_{1.5} \mathrm{I}_{1.5}$ perovskite quantum dots with 9,9-dihexylfluorene co-oligomer for white electroluminescence. Org. Electron. 2017, 44, 6-10. [CrossRef]

(C) 2020 by the authors. Licensee MDPI, Basel, Switzerland. This article is an open access article distributed under the terms and conditions of the Creative Commons Attribution (CC BY) license (http://creativecommons.org/licenses/by/4.0/). 